\title{
Understanding Smokers' Motivations to Use Evidence- based Smoking Cessation Aids
}

Citation for published version (APA):

Willems, R. A., Willemsen, M. C., Nagelhout, G. E., \& de Vries, H. (2013). Understanding Smokers' Motivations to Use Evidence-based Smoking Cessation Aids. Nicotine \& Tobacco Research, 15(1), 167176. https://doi.org/10.1093/ntr/nts104

Document status and date:

Published: 01/01/2013

DOI:

10.1093/ntr/nts104

Document Version:

Publisher's PDF, also known as Version of record

Document license:

Taverne

Please check the document version of this publication:

- A submitted manuscript is the version of the article upon submission and before peer-review. There can be important differences between the submitted version and the official published version of record.

People interested in the research are advised to contact the author for the final version of the publication, or visit the DOI to the publisher's website.

- The final author version and the galley proof are versions of the publication after peer review.

- The final published version features the final layout of the paper including the volume, issue and page numbers.

Link to publication

\footnotetext{
General rights rights.

- You may freely distribute the URL identifying the publication in the public portal. please follow below link for the End User Agreement:

www.umlib.nl/taverne-license

Take down policy

If you believe that this document breaches copyright please contact us at:

repository@maastrichtuniversity.nl

providing details and we will investigate your claim.
}

Copyright and moral rights for the publications made accessible in the public portal are retained by the authors and/or other copyright owners and it is a condition of accessing publications that users recognise and abide by the legal requirements associated with these

- Users may download and print one copy of any publication from the public portal for the purpose of private study or research.

- You may not further distribute the material or use it for any profit-making activity or commercial gain

If the publication is distributed under the terms of Article $25 \mathrm{fa}$ of the Dutch Copyright Act, indicated by the "Taverne" license above, 


\title{
Original Investigation \\ Understanding Smokers' Motivations to Use Evidence-based Smoking Cessation Aids
}

\author{
Roy A. Willems, M.Sc., ${ }^{1,2}$ Marc C. Willemsen, Ph.D., ${ }^{1,3}$ Gera E. Nagelhout, M.Sc., ${ }^{1,3}$ \& Hein de Vries, Ph.D. ${ }^{1}$ \\ ${ }^{1}$ Department of Health Promotion, School for Public Health and Primary Care (CAPHRI), Maastricht University, Maastricht, The Netherlands \\ ${ }^{2}$ School of Psychology, Open University of the Netherlands, Heerlen, The Netherlands \\ ${ }^{3}$ STIVORO, Dutch Expert Centre on Tobacco Control, The Hague, The Netherlands
}

Corresponding Author: Roy A. Willems, M.Sc., School of Psychology, Open University of the Netherlands, P.O. Box 2960, 6401 DL Heerlen, The Netherlands. Telephone: +31-45-576-2763; Fax: +31-45-576-2800; E-mail: roy.willems@ou.nl

Received November 15, 2011; accepted March 6, 2012

\section{Abstract}

Introduction: Use of evidence-based smoking cessation aids (SCA) is an efficacious way to improve smoking cessation relapse rates. However, use of SCA in the Netherlands is particularly low. This study examined determinants of intention to use SCA in smokers willing to quit.

Methods: The Dutch Continuous Survey of Smoking Habits, a cross-sectional population survey, was used. Respondents were smokers $(n=594)$ wanting to quit sometime in the future and who made at least one quit attempt in the past, categorized as past users of evidence-based SCA, past users of nonevidencebased SCA, and smokers who had never used SCA before (nonusers). Respondents were asked about past SCA use, motivational determinants regarding smoking cessation and SCA use, and intention to use SCA during a future quit attempt.

Results: Older and more addicted smokers were more likely to have used evidence-based SCA. Evidence-based and nonevidence-based users reported stronger attitudes and perceived social norm as well as lower self-efficacy expectations regarding smoking cessation and SCA use than nonusers. Having positive outcome expectations and perceived social norm regarding SCA use were strong predictors of intention to use SCA. Self-efficacy regarding smoking cessation was negatively related with intention to use SCA.

Conclusions: Nonusers, nonevidence-based users, and evidencebased users have different motivations for using evidence-based SCA and should not be treated as a homogenous group in smoking cessation programs. Additionally, it is unclear whether nonusers should be encouraged to use SCA, given that this group is less addicted and more confident about quitting.

\section{Introduction}

Cigarette smoking remains one of the most important causes of attributable death and disease in the world (Lopez, Mathers, Ezzati, Jamison, \& Murray, 2006). In the Netherlands, about 27\%

doi:10.1093/ntr/nts104

Advance Access publication May 9, 2012

(C) The Author 2012. Published by Oxford University Press on behalf of the Society for Research on Nicotine and Tobacco.

All rights reserved. For permissions, please e-mail: journals.permissions@oup.com of the Dutch population smokes, of whom $80 \%$ want to quit (STIVORO, 2011). Yet, without assistance, only 7\% of quit attempts are successful (U.S. Public Health Service, 2000; Zhu, Melcer, Sun, Rosbrook, \& Pierce, 2000). Encouraging smokers to use evidence-based smoking cessation aids (SCA) may increase smoking cessation success rates. According to guidelines, pharmacotherapy (consisting of nicotine replacement therapy and medication) and professional support are efficacious SCA, while a combination of the two is regarded as the most effective, increasing success rates by a factor of 4 in randomized clinical trials and a factor of 2 under real-world conditions (Gibson et al., 2010; Partnership on smoking cessation, 2006; U.S. Public Health Service, 2000; Zhu et al., 2000). Computer-tailored interventions are considered to be effective self-help materials (Lancaster, Stead, Silagy, \& Sowden, 2000; Partnership on smoking cessation, 2006). In the Netherlands, a wide array of effective SCA is available (Willemsen, Wagena, \& van Schayck, 2003), but use remains low. For example, only $18 \%$ of Dutch smokers use pharmacotherapy during a quit attempt, which is much lower compared with other Western countries, such as the United States (40\%) and the United Kingdom (47\%). Additionally, only $8 \%$ of Dutch smokers are advised to quit smoking by professionals during the year, compared with $51 \%$ in the United States and 28\% in the United Kingdom (International Tobacco Control Policy Evaluation Project, 2010). This paper aims to explore the most important determinants for Dutch smokers (not) to use SCA, and how they can be assisted in quitting more successfully.

Various barriers to SCA use have been reported elsewhere. In a longitudinal population study, Gross et al. (2008) identified various beliefs held by smokers for not using SCA: help is not necessary, smoking is not perceived as a big problem in one's life, SCA are not helpful or too expensive, and one should be able to quit on one's own (Weinstein, Slovic, \& Gibson, 2004). Smokers have been found to lack knowledge about the different kinds of SCA and their effectiveness (Hammond, McDonald, Fong, \& Borland, 2004) or to have been misinformed about the safety and efficacy of nicotine replacement therapy (Bansal, Cummings, Hyland, \& Giovino, 2004; Cummings et al., 2004), making them less likely to use this treatment (Ferguson et al., 2011). 
Previous studies on the demographic determinants of SCA use found that the use of SCA is higher among smokers who are female, older, smoke more cigarettes per day, have higher levels of nicotine dependence, higher education, and who planned a quit attempt (Kotz, Fidler, \& West, 2009; Shiffman, Brockwell, Pillitteri, \& Gitchell, 2008a). Smokers with a low socioeconomic status (SES) are less likely to use professional support (Kotz et al., 2009), while women are more likely to do so. More educated smokers and women are more likely to combine pharmacotherapy and professional support; while men, older smokers, and more nicotine dependent smokers are more likely to use pharmacotherapy (Shiffman et al., 2008a). In general, pharmacotherapy is much more used than behavioral counseling (Cokkinides, Ward, Jemal, \& Thun, 2005; Kotz et al., 2009).

An important limitation of previous research is that most studies focus on reasons why smokers in general may not use SCA, rather than distinguishing between smokers who have never used SCA and those who have. By examining specific reasons for (not) using SCA, strategies can be developed directed at the specific needs and motivations of these groups. Additionally, although previous research has described several determinants for using SCA, the relationship of these determinants with intention to use SCA, as well as the relative importance of these determinants, have not yet been investigated. Our study therefore had two goals. First, we aimed to assess potential motivational differences regarding smoking cessation and SCA use between smokers who had used SCA in the past and those who had not. Among past SCA users, we compared smokers who had used evidence-based SCA with those who had used nonevidence-based SCA. Second, we assessed which determinants are most important in understanding the intention to use SCA. The results should give more insight into how to help smokers to quit more successfully.

\section{Methods}

\section{Design and Procedure}

Data were obtained from the Dutch Continuous Survey of Smoking Habits (DCSSH), a cross-sectional population survey aimed at monitoring the smoking behavior of the Dutch population aged 15 years and older. Respondents for the DCSSH were randomly selected from the TNS NIPObase, a large probability-based database with over 140,000 potential Dutch web respondents who have indicated their willingness to participate in research on a regular basis. TNS NIPObase panel members are actively recruited by TNS NIPO. People cannot apply for participation, which results in a low number of professional and inattentive respondents (Van Ossenbruggen, Vonk, \& Willems, 2006). Web panel members are recruited by telephone or e-mail but not by Internet.

The data for the current study were collected between October and December 2010. In total, 6,746 respondents were approached, of whom 4,571 participated in the study. Of these, 1,219 respondents indicated that they smoked. These smokers were asked to indicate whether they intended to quit smoking sometime in the future: $12.4 \%$ answered "yes, within a month," $14.1 \%$ "yes, within 1-6 months," 14.3\% "yes, within 6 months and 1 year," 39.7\% "yes, but not within a year," and 19.5\% "no, never." Smokers who answered "No, never" were excluded.
Finally, of the smokers having the intention to quit smoking sometime in the future, 594 smokers had made at least one quit attempt in the past. This group was used for analysis. The results reported in this paper are weighted by gender, age, and educational level, working hours, geographic region, urbanization, and household size.

\section{Measures \\ Past SCA Use}

Smokers were asked to indicate whether they had used any cessation aids during a past quit attempt. Smokers who had used evidence-based SCA in the past, such as pharmacotherapy, professional support, and/or tailored advice were categorized as "evidence-based SCA users." Smokers were also classified into this group if they had used nonevidence-based SCA next to evidence-based SCA. Smokers who had only used nonevidencebased SCA, such as nonevidence-based self-help materials and/ or alternative therapy were categorized as "nonevidence-based SCA users." Finally, smokers who had never used SCA were categorized as "nonusers." Pharmacotherapy included nicotine replacement therapy, Zyban/bupropion, nortriptyline/Nortrilen, and Champix/varenicline. Professional support included cessation advice from a professional, psychological/behavioral therapy, quit line counseling, and group training. Nonevidence-based self-help materials included books, brochures, Internet sites, and a Smartphone application. Alternative therapy included acupuncture and laser therapy.

\section{Predisposing Factors}

Predisposing factors were age, gender, SES, level of nicotine dependence, and number of past quit attempts. SES was calculated using an index based on the respondents' educational level and profession and was classified into three categories (low, middle, and high). The Heaviness of Smoking Index (HSI) was used to measure level of nicotine dependence. The HSI is measured by combining two variables: the time between waking up and the first cigarette of the day and the number of cigarettes smoked per day (Heatherton, Kozlowski, Frecker, Rickert, \& Robinson, 1989). To conduct group comparisons, the HSI was categorized into three groups: those who scored $0-1$ were categorized as low, 2-4 as middle, and $5-6$ as high in nicotine dependence (Chaiton, Cohen, McDonald, \& Bondy, 2007). Number of past quit attempts was measured by asking smokers how many quit attempts they had undertaken in the past. Answers ranged between 0 and 96, but since there was a clear cutoff point at 6 quit attempts, all answers of 6 and higher were recoded as 6 .

\section{Motivational Factors}

Attitude was described as the perceived advantages and disadvantages of engaging in a certain behavior (De Vries, Lezwijn, Hol, \& Honing, 2005) and was measured on a 4-point scale ranging from 1 ("disagree") to 4 ("totally agree") by asking smokers whether they agreed with several questions about positive (four items; $\alpha=.64$ ) and negative (four items; $\alpha=.71$ ) outcome expectations of smoking cessation and positive (two items; $\alpha=.80$ ) and negative (two items; used separately because of low internal consistency) outcome expectations of SCA use. Additionally, attitude was measured by asking smokers to indicate the extent to which they thought SCA users were sensible, courageous, dependent, taking things too easily, determined, soft, weak, naïve, smart, and addicted $(\alpha=.84)$. Items ranged from 1 ("not at all ...") to 7 ("very ..."). (Perceived) social norm 
was described as the (perception of the) norms of the environment with respect to a certain behavior (De Vries et al., 2005) and was measured on a 5-point scale ranging from 1 ("totally disagree") to 5 ("totally agree") by one item asking smokers about the perceived social norm of smoking cessation and one item about the perceived social norm of using SCA. Self-efficacy was described as the perception of one's capability of performing a certain behavior (De Vries et al., 2005) and was measured on a 5 -point scale ranging from 1 ("very difficult") to 5 ("not difficult at all") by three items asking how difficult smokers would find it not to smoke in certain situations $(\alpha=.79)$ and three items asking how difficult they would find it to use SCA $(\alpha=.83)$.

\section{Intention to Use SCA}

Intention to use SCA was measured by one item on a 5-point scale ranging from 1 ("definitely not") to 5 ("definitely"), asking "Do you intend to use aids, methods or professional help when you try to quit smoking?"

\section{Analyses}

Chi-square tests were used to find differences in past SCA use among different age groups, genders, SES, and levels of nicotine dependence. Differences in Ms regarding the motivational factors between evidence-based, nonevidence-based, and nonusers were analyzed using ANOVAs. Contrasts were analyzed using the Games-Howell procedure due to uncertainty regarding whether equal variances could be assumed and inequality of group sizes (Field, 2009). Before scaling the items, calculating correlations, and conducting regression analysis, multiple imputation with 15 imputations was conducted to fill in any missing values (Schafer \& Graham, 2002; with “don't know" answer options recoded as missing). Multiple imputation calculated what the missing value was expected to be taking all other relevant data into account.
To examine significant determinants of the intention to use SCA, a correlation matrix and a hierarchical multiple regression analysis were conducted. The latter consisted of three steps with intention to use SCA as dependent variable. Age, gender, SES, HSI, and past SCA use were included in the first step of the model, assuming that predisposing factors precede the development of motivational factors (De Vries et al., 2005). Motivational factors regarding quitting smoking were entered in the second step and motivational factors regarding the use of SCA in the third, in order to explore the unique contributions of these two dimensions. Data were analyzed using SPSS 19.0, and results considered significant when $p<.05$.

\section{Results}

\section{Demographics and Use of SCA}

Mean age of the respondents was 42.11 years $(S D=14.06)$. Overall, $50.4 \%$ of the smokers indicated that they had used some form of treatment in the past. Of these, $15.9 \%$ had used nonevidence-based SCA only, while $34.5 \%$ had used evidencebased SCA. Pharmacotherapy was the most commonly used SCA $(28.6 \%)$, while $2.7 \%$ had used only professional support and $3.3 \%$ had used both pharmacotherapy and professional support. Of all respondents, $35.2 \%$ of the smokers indicated that they probably or definitely intended to use SCA during a future quit attempt.

Table 1 shows the demographics of evidence-based users, nonevidence-based users, and nonusers. The results of the logistic regression models show that, in general, evidence-based users were older and more addicted smokers and nonusers were younger and less addicted smokers. Furthermore, evidence-based users

\section{Table 1. Demographic Characteristics of Evidence-based Users $(n=295)$, Nonevidence- based Users $(n=94)$, and Nonusers $(n=205)$}

\begin{tabular}{|c|c|c|c|c|c|c|c|}
\hline $\begin{array}{l}\text { Predisposing } \\
\text { factor }\end{array}$ & $n(\%)$ & No SCA used (\%) & $\begin{array}{l}\text { Unadjusted } O R \\
(95 \% C I)\end{array}$ & $\begin{array}{l}\text { Nonevidence- } \\
\text { based users (\%) }\end{array}$ & $\begin{array}{l}\text { Unadjusted } O R \\
(95 \% C I)\end{array}$ & $\begin{array}{l}\text { Evidence-based } \\
\text { SCA used (\%) }\end{array}$ & $\begin{array}{l}\text { Unadjusted } O R \\
(95 \% C I)\end{array}$ \\
\hline \multicolumn{8}{|l|}{ Gender } \\
\hline Male & $268(45.1)$ & 51.7 & 1.00 & 14.6 & 1.00 & 33.7 & 1.00 \\
\hline Female & $326(54.9)$ & 47.9 & $0.86(0.62-1.19)$ & 16.9 & $1.20(0.77-1.88)$ & 35.1 & $1.06(0.76-1.49)$ \\
\hline \multicolumn{8}{|l|}{ Age (years) } \\
\hline $15-24$ & $71(12.0)$ & 64.8 & 1.00 & 11.3 & 1.00 & 23.9 & 1.00 \\
\hline $25-34$ & $124(20.9)$ & 57.3 & $0.75(0.41-1.37)$ & 19.4 & $1.86(0.80-4.33)$ & 22.6 & $0.94(0.47-1.86)$ \\
\hline $35-44$ & $152(25.6)$ & 47.4 & $0.50(0.28-0.89)^{\star}$ & 15.0 & $1.32(0.56-3.08)$ & 37.5 & $1.92(1.02-3.63)^{*}$ \\
\hline $45-54$ & $124(20.8)$ & 43.5 & $0.43(0.24-0.79)^{\star *}$ & 13.8 & $1.24(0.51-3.00)$ & 42.7 & $2.31(1.21-4.43)^{*}$ \\
\hline 55 and older & $122(20.6)$ & 41.8 & $0.39(0.22-0.72)^{\star *}$ & 18.0 & $1.64(0.69-3.86)$ & 41.0 & $2.18(1.14-4.19)^{\star}$ \\
\hline \multicolumn{8}{|l|}{ SES } \\
\hline Low & $240(40.4)$ & 45.8 & 1.00 & 18.8 & 1.00 & 35.4 & 1.00 \\
\hline Middle & $111(18.7)$ & 50.9 & $1.22(0.87-1.92)$ & 17.6 & $0.76(0.41-1.40)$ & 34.2 & $0.92(0.56-1.49)$ \\
\hline High & $243(41.0)$ & 52.7 & $1.32(0.92-1.89)$ & 13.6 & $0.69(0.42-1.12)$ & 33.7 & $0.64(0.43-0.96)^{*}$ \\
\hline \multicolumn{8}{|c|}{$\begin{array}{l}\text { Heaviness of } \\
\quad \text { Smoking Index }\end{array}$} \\
\hline Low & $182(33.7)$ & 62.1 & 1.00 & 11.0 & 1.00 & 26.9 & 1.00 \\
\hline Middle & $321(59.3)$ & 43.6 & $0.47(0.32-0.68)^{* * *}$ & 18.1 & $1.81(1.05-3.13)^{*}$ & 38.3 & $1.69(1.14-2.53)^{\star \star}$ \\
\hline High & $38(7.0)$ & 16.2 & $0.12(0.50-0.30)^{\star \star \star}$ & 23.7 & $2.44(1.00-5.93)$ & 60.5 & $4.12(1.99-8.52)^{\star * \star}$ \\
\hline
\end{tabular}

Note. Differences between numbers or percentages within a category and the total are attributable to rounding off of weighted values.

${ }^{\mathrm{a}} n=541$.

${ }^{*} p<.05 .{ }^{* *} p<.01 .{ }^{* * *} p<.001$. 
$(M=2.56, S D=1.54)$ and nonevidence-based users $(M=2.59$, $S D=1.45)$ had similar HSI results, both scoring higher on the HSI than nonusers $(M=1.88, S D=1.12 ; F(2,538)=15.71, p<$ $\left..001, \omega^{2}=.05\right)$. Additionally, evidence-based users $(M=3.20$, $S D=1.55)$ had made more quit attempts than nonusers $(M=$ $2.65, S D=1.58)$, while nonevidence-based users $(M=2.82, S D$ $=1.60)$ did not significantly differ from evidence-based users and nonusers $\left(F(2,590)=40.98, p<.01, \omega^{2}=.02\right)$.

\section{Beliefs About Quitting Smoking and Using SCA}

Differences in motivational factors between nonusers, evidencebased users, and nonevidence-based users were analyzed. The results show that both groups of SCA users held significantly more positive attitudes, encountered a more positive social norm, and reported lower self-efficacy toward smoking cessation and SCA use (Table 2). Most of these differences were found between evidence-based users and nonusers. Furthermore, relatively more nonusers and nonevidence-based users reported "don't know" on items asking about SCA use. Finally, nonusers scored significantly lower on intention to use SCA than nonevidence-based users, who in turn scored significantly lower than evidence-based users.

The overall effect sizes of differences between groups concerning outcome expectations for smoking cessation were small compared with the overall effect sizes of outcome expectations for SCA use. Effect sizes of .01, .06, and .14 were considered small, medium, and large, respectively (Kirk, 1996). Important differences in this regard were found for items asking about selfconfidence to quit when using SCA $\left(\omega^{2}=.12\right)$, ability to quit successfully when using SCA $\left(\omega^{2}=.14\right)$, (perceived) attitudes of those in the smoker's environment with respect to getting help when quitting smoking $\left(\omega^{2}=.14\right)$, and intention to use SCA during a future quit attempt $\left(\omega^{2}=.33\right)$.

\section{Determinants of Intention to Use SCA}

The second objective was to analyze which determinants were most strongly associated with the intention to use SCA. Use of evidence-based SCA $(r=.51, p<.001)$, attitude in favor of using SCA $(r=.67, p<.001)$, and perceived social norm regarding SCA use $(r=.53, p<.001)$ were strongly related to the intention to use SCA (Table 3 ). To explore the unique contribution of the predisposing and motivational factors on intention to use SCA, a hierarchical multiple regression analysis was conducted (Table 4). In the final model of the analysis, 10 variables remained significant predictors of the intention to use SCA $(F(17,593)=$ $60.18, p<.001$ ). Being male, being older, use of nonevidencebased SCA, use of evidence-based SCA, and having a higher level of nicotine dependence, a positive attitude toward SCA, a positive perception of SCA users, and greater perceived social norm regarding SCA use were all positively related to the intention to use SCA. Self-efficacy regarding smoking cessation and believing that the cost involved in using SCA is problematic were negatively related to the intention to use SCA. This model explained $63 \%$ of the total variance for the intention to use SCA.

\section{Discussion}

The aim of the current study was to examine motivational differences regarding smoking cessation and SCA use between past users of evidence-based SCA, past users of nonevidence-based SCA, and nonusers, and to examine which determinants are most strongly related to the intention to use SCA by way of a hierarchical regression model. This model explained $63 \%$ of the variance of predisposing and motivational factors predicting intention to use SCA, which fits with the range of explained variance reported in similar studies (Armitage \& Conner, 2001).

The main finding is that smokers with a positive attitude toward SCA use (i.e., those who expect SCA to give them more confidence and to make them better able to quit smoking) had the highest intention to use SCA during a future quit attempt. That evidence-based and nonevidence-based users agreed more on these beliefs than nonusers may reflect a lack of positive outcome expectations regarding SCA use among smokers with no experience with SCA (Gross et al., 2008). This might be driven by misperceptions about the health risks of SCA (Bansal et al., 2004), lack of knowledge about effectiveness, or lack of experience (Hammond et al., 2004). When asked how they would feel if they never smoked again, nonusers expected to experience the least distress. In addition, both groups of SCA users expected a greater burden of withdrawal effects during smoking cessation, were more addicted, and reported lower self-efficacy regarding smoking cessation and SCA use than nonusers, while high self-efficacy regarding smoking cessation was negatively related to intention to use SCA. This indicates that smokers who believed they would be able to abstain from smoking in challenging situations were less likely to use SCA.

Another important difference between the groups was that SCA users perceived a more positive social norm regarding SCA use than nonusers, with evidence-based SCA users experiencing the strongest social norm. This norm was also a strong predictor of intention to use SCA, indicating that a supportive environment is important for aided smoking cessation. This might also imply that smokers who tend to use SCA are part of a social network of fellow users. More research should examine the mechanisms through which usage of novel evidence-based SCA spreads through social networks, and whether this might differ from how nonevidence-based SCA is diffused. A better understanding of these processes might help to increase the diffusion of evidence-based SCA and reduce nonevidence-based SCA.

The importance of costs as a barrier to SCA use has been observed previously (Gross et al., 2008), and our regression model confirmed this. In addition, we found that this belief is negatively related to intention to use SCA during a future quit attempt. These results support research demonstrating that reimbursing the costs of SCA increases SCA use and fosters more successful quit attempts (Kaper, Wagena, Willemsen, \& van Schayck, 2005, 2006).

The present results give rise to the question how important the lack of positive outcome expectations regarding SCA use is for nonusers, since these smokers are less addicted, expect less distress during smoking cessation, and report higher levels of self-efficacy during smoking cessation than SCA users. Evidently, high self-efficacy and feelings of control over withdrawal symptoms are important for successfully quitting smoking (DiClemente, 1981; Schnoll et al., 2011; Williams et al., 2006). An interesting contradiction seems to exist: nonusers reported low motivation to quit but high self-efficacy concerning smoking cessation and SCA use; whereas SCA users reported high motivation but low 
Nicotine \& Tobacco Research, Volume 15, Number 1 (January 2013)
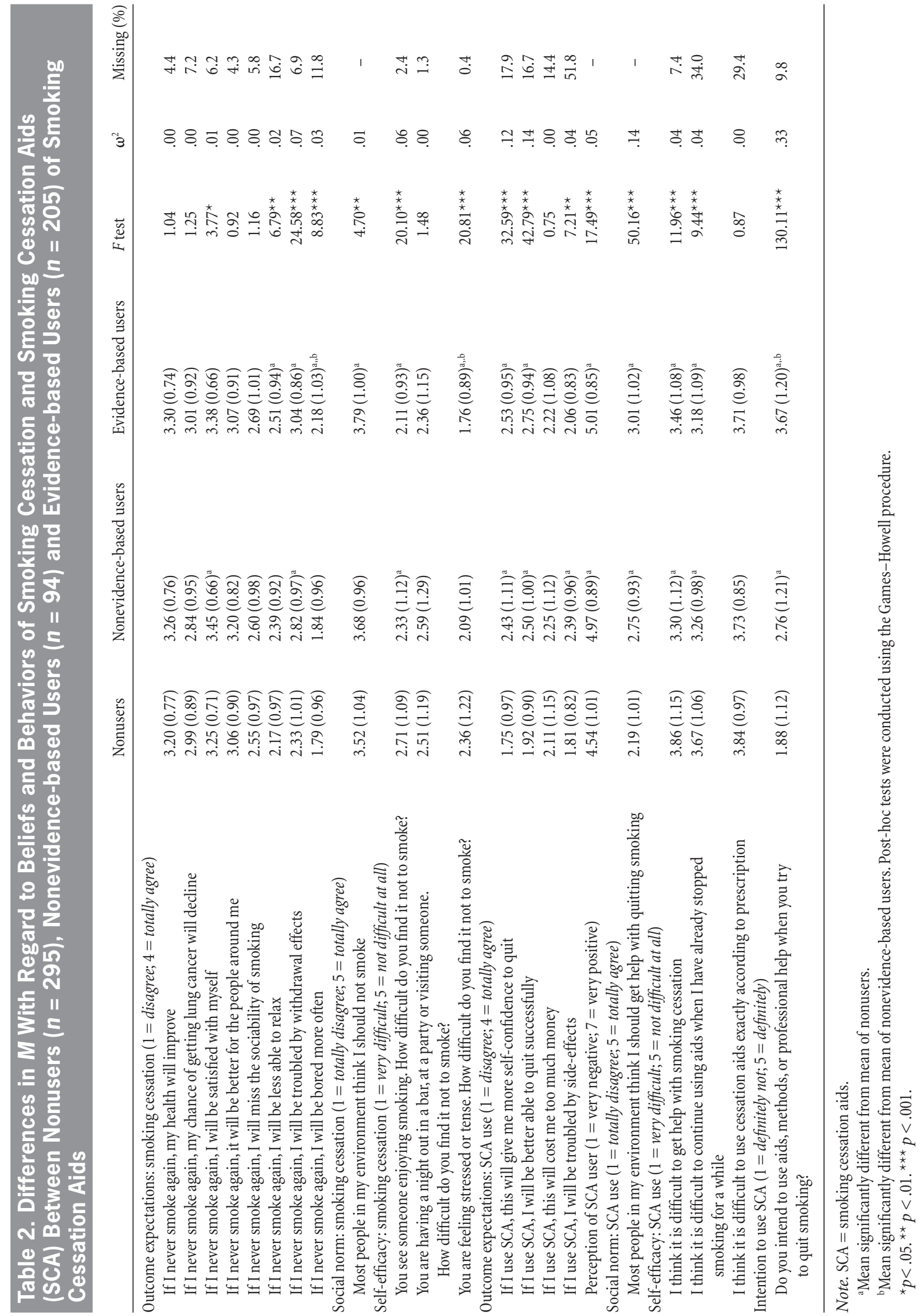

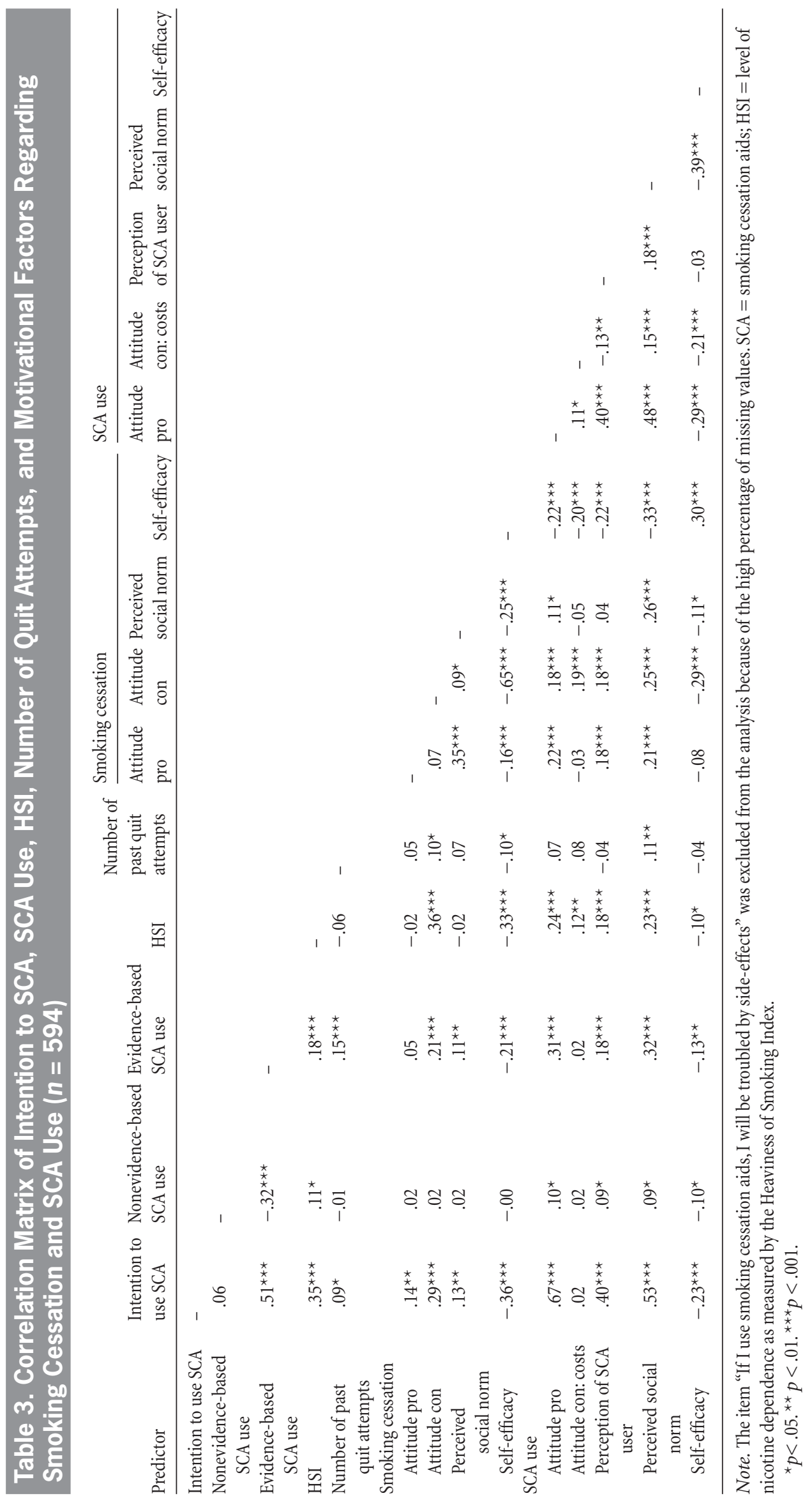
Nicotine \& Tobacco Research, Volume 15, Number 1 (January 2013)

Table 4. Summary of Hierarchical Regression Analysis of Several Determinants Predicting

the Intention to Use SCA with Beta Weights and Their Standard Errors $(n=594)$

\begin{tabular}{|c|c|c|c|c|c|c|}
\hline \multirow[b]{3}{*}{ Determinant } & \multicolumn{6}{|l|}{ Model } \\
\hline & \multicolumn{2}{|l|}{ Step 1} & \multicolumn{2}{|l|}{ Step 2} & \multicolumn{2}{|l|}{ Step 3} \\
\hline & $B$ & $S E B$ & $B$ & SE B & $B$ & SE B \\
\hline Gender (reference: male) & $.31^{* *}$ & .10 & $.26^{* *}$ & .09 & $.16^{*}$ & .08 \\
\hline Age & .00 & .00 & .00 & .00 & $.01^{\star}$ & .00 \\
\hline \multicolumn{7}{|l|}{ SES (reference: low) } \\
\hline Middle & .00 & .00 & .00 & .13 & .03 & .10 \\
\hline High & .00 & .13 & .02 & .10 & .10 & .08 \\
\hline HSI & $.22^{* * *}$ & .03 & $.17^{\star * *}$ & .04 & $.09^{\star *}$ & .03 \\
\hline Number of past quit attempts & .03 & .03 & .01 & .03 & .01 & .02 \\
\hline \multicolumn{7}{|l|}{ Past SCA use (reference: nonuse) } \\
\hline Nonevidence-based SCA use & $.73^{\star * *}$ & .14 & $.70^{* * *}$ & .14 & $.28^{*}$ & .12 \\
\hline Evidence-based SCA use & $1.52^{\star * *}$ & .11 & $1.42^{\star * \star}$ & .11 & $.83^{* * *}$ & .10 \\
\hline \multicolumn{7}{|l|}{ Smoking cessation } \\
\hline Attitude pro & & & $.21^{\star}$ & .09 & -.07 & .08 \\
\hline Attitude con & & & -.03 & .10 & -.01 & .08 \\
\hline Perceived social norm & & & .01 & .05 & -.03 & .04 \\
\hline Self-efficacy & & & $-.28^{\star * *}$ & .07 & $-.20^{\star \star}$ & .06 \\
\hline \multicolumn{7}{|l|}{ Using SCA } \\
\hline Attitude pro & & & & & $.64^{* * *}$ & .05 \\
\hline Attitude con: costs & & & & & $-.09^{*}$ & .04 \\
\hline Perception of SCA user & & & & & $.11^{\star}$ & .05 \\
\hline Perceived social norm & & & & & $.25^{\star \star \star}$ & .05 \\
\hline Self-efficacy & & & & & .06 & .05 \\
\hline$R^{2}$ (adjusted) $)^{\mathrm{a}}$ & $.37(.35-.40)$ & & $.40(.39-.42)$ & & $.63(.62-.64)$ & \\
\hline
\end{tabular}

Note. The item "If I use smoking cessation aids, I will be troubled by side-effects" was left out of the analysis because of the high percentage of missing values. SCA = smoking cessation aids; HSI = level of nicotine dependence as measured by the Heaviness of Smoking Index.

${ }^{a} R^{2}$ (adjusted) is based on the $M$ value of the values given by the 15 imputations, with minimum and maximum $R^{2}$ (adjusted) between brackets. ${ }^{*} p<.05 .{ }^{* *} p<.01 .{ }^{* *} p<.001$.

self-efficacy to quit and use SCA. The question arises who benefits most from using SCA. It is argued that those who use SCA are less successful in smoking cessation than those who do not use SCA, which can be partially explained by their heaviness of smoking (Shiffman, Brockwell, Pillitteri, \& Gitchell, 2008b; Zhu et al., 2000). This might indicate that SCA would have more benefit for nonusers. However, the effectiveness of some SCA depends on smokers' motivation to quit (Silagy, Lancaster, Stead, Mant, \& Fowler, 2004). It is conceivable that nonusers and SCA users may need different strategies for successful smoking cessation. Longitudinal research is thus needed to assess potential differential predictors of success in SCA users and nonusers. Yet, given that many quitters relapse, it is also conceivable that this may also occur among nonusers, which may then imply that their self-efficacy estimations were overoptimistic.

Nonevidence-based users, who had no experience with evidence-based SCA, reported lower intention to use evidencebased SCA in the future than evidence-based users. However, nonevidence-based users were no less addicted to smoking than evidence-based users. This difference might be due to the fact that this group is particularly fearful of the side effects associated with SCA use (Sood, Ebbert, Sood, \& Stevens, 2006), which suggests that educating nonevidence-based users on the low incidence of side effects might be helpful. Otherwise, there were relatively few differences between evidence-based and nonevidencebased users. This could indicate that the distinction between evidence-based and nonevidence-based SCA is less clear for smokers than for professionals. This distinction is evidently not clear in practice either, since alternative therapy is promoted as a treatment for smoking cessation without clear evidence of its effectiveness (White, Rampes, Liu, Stead, \& Campbell, 2011). New research could investigate how educational materials can outline the distinction between evidence-based and non-evidence-based SCA more clearly and how this could influence the choice between different types of SCA.

A limitation of the present study is that it was based on cross-sectional data, making it impossible to interpret causality from the observed relationships. Longitudinal data should therefore be collected in future studies. Second, since this study was Internet-based, the results might not fully represent the Dutch population. However, the Internet penetration in the Netherlands is very high: $94 \%$ of the Dutch population has Internet access (Special Eurobarometer 362, 2011). Furthermore, we used a high quality Internet panel that has proven to be a good alternative to telephone interviewing in the Netherlands (Nagelhout et al., 2010). Another limitation is that we used self-reported data about SCA use. Not all smokers may recall their history of SCA use, which may have introduced recall bias. 
However, specific SCA were categorized into three broad categories, making it less likely that this would have influenced the observed associations. A final potential limitation is that we used the broad categories of evidence- and nonevidence-based users, obscuring differences such as those between users of pharmacotherapy, professional support, and tailored advice within the evidence-based category. This was necessary because of the relatively small number of respondents using professional support or tailored advice. In other studies, too, it is not uncommon for these aids to be underused (Cokkinides et al., 2005; Kotz et al., 2009).

The main implication of this study is that increasing positive outcome expectations of SCA use, self-efficacy expectation regarding smoking cessation, and the (perceived) social norm of using SCA are important determinants to be targeted in future interventions encouraging smokers to use SCA. Further, it is important to acknowledge that different strategies may be needed for each SCA group: nonusers could be informed of the benefits of using SCA, nonevidence-based users could benefit from education about the safety of pharmacotherapy, and evidence-based users could be encouraged to continue using SCA. In practice, this could mean that health professionals, such as general practitioners, should not only encourage smokers to quit smoking but also understand their history of (quitting) smoking, including number of past quit attempt, type of SCA used, and self-efficacy expectations regarding smoking cessation in order to develop specific plans to quit more successfully.

However, it is worth noting that increasing the use of treatment is only part of the solution to decrease population smoking rates: an increase in the total number of quit attempts is also necessary to achieve this goal (Levy, Mabry, Graham, Orleans, \& Abrams, 2010). Additionally, whether SCA should be heavily promoted in smokers' populations remains a topic of debate (Chapman \& MacKenzie, 2010; West et al., 2010). The argument against it is that, from a population-level perspective, most smokers who quit successfully have managed to do so unassisted, and promoting the use of SCA could unintentionally dissuade large groups of smokers who are capable of quitting unassisted from doing so (Chapman \& MacKenzie, 2010; Pierce, Cummins, White, Humphrey, \& Messer, 2012). Our data also revealed that many smokers with no experience with SCA are less addicted and report high self-efficacy toward quitting, that is, they are confident that they can quit if they choose to do so. Our data provide no clear conclusion on whether these smokers should be targeted with messages to use SCA.

\section{Funding}

This work was supported by Minder Rokers (MIRO): innovation in smoking cessation (MIROKPJ-011-090730).

\section{Declaration of Interests}

The funder had no involvement in the design of the study, the collection, analysis or interpretation of the data, the writing of the paper, or the decision to submit the paper for publication.

\section{Acknowledgments}

We would like to thank STIVORO, the Dutch Expert Centre on Tobacco Control, for using the DCSSH data. This survey was supported by grants from the Dutch Ministry of Health, Welfare and Sport. Finally, we would like to thank Carolien Thush for her contribution to the design of this study and for drafting the questionnaire.

\section{References}

Armitage, C. J., \& Conner, M. (2001). Efficacy of the theory of planned behaviour: A meta-analytic review. British Journal of Social Psychology, 40, 471-499. doi:10.1348/014466601164939

Bansal, M. A., Cummings, K. M., Hyland, A., \& Giovino, G. A. (2004). Stop-smoking medications: Who uses them, who misuses them, and who is misinformed about them? Nicotine \& Tobacco Research, 6, 303-310. doi:10.1080/14622200412331320707

Chaiton, M. O., Cohen, J. E., McDonald, P. W., \& Bondy, S. J. (2007). The Heaviness of Smoking Index as a predictor of smoking cessation in Canada. Addictive Behaviors, 32, 1031-1042. doi:10.1016/j.addbeh.2006.07.008

Chapman, S., \& MacKenzie, R. (2010). The global research neglect of unassisted smoking cessation: Causes and consequences. PLoS Medicine, 7, e1000216. doi:10.1371/journal. pmed.1000216

Cokkinides, V. E., Ward, E., Jemal, A., \& Thun, M. J. (2005). Under-use of smoking-cessation treatments: Results from the National Health Interview Survey, 2000. American Journal of Preventive Medicine, 28, 119-122. doi:10.1016/j.ampre.2004.09.007

Cummings, K. M., Hyland, A., Giovino, G. A., Hastrup, J. L., Bauer, J. E., \& Bansal, M. A. (2004). Are smokers adequately informed about the health risks of smoking and medicinal nicotine? Nicotine \& Tobacco Research, 6, 333-340. doi:10.1080/146 22200412331320734

De Vries, H., Lezwijn, J., Hol, M., \& Honing, C. (2005). Skin cancer prevention: Behaviour and motives of Dutch adolescents. European Journal of Cancer Prevention, 14, 39-50. doi:10.1097/00008469-200502000-00006

DiClemente, C. C. (1981). Self-efficacy and smoking cessation maintenance: A preliminary report. Cognitive Therapy and Research, 5, 175-187. doi:10.1007/BF01172525

Ferguson, S. G., Gitchell, J. G., Shiffman, S., Sembower, M. A., Rohay, J. M., \& Allen, F. (2011). Providing accurate safety information may increase a smoker's willingness to use nicotine replacement therapy as part of a quit attempt. Addictive Behaviors, 36, 713-716. doi:10.1016/j.addbeh.2011.02.002

Field, A. (2009). Discovering statistics using SPSS (3rd ed.). London: SAGE Publications.

Gibson, J. E., Murray, R. L., Borland, R., Cummings, K. M., Fong, G. T., Hammond, D., \& McNeill, A. (2010). The impact of the United Kingdom's national smoking cessation strategy on quit attempts and use of cessation services: Findings from 
the International Tobacco Control Four Country Survey. Nicotine \& Tobacco Research, 12, S64-S71. doi:10.1093/ntr/ ntq119

Gross, B., Brose, L., Schumann, A., Ulbricht, S., Meyer, C., Völzke, H., et al. (2008). Reasons for not using smoking cessation aids. BMC Public Health, 8, 129-137. doi:10.1186/1471-2458-8-129

Hammond, D., McDonald, P. W., Fong, G. T., \& Borland, R. (2004). Do smokers know how to quit? Knowledge and perceived effectiveness of cessation assistance as predictors of cessation behaviour. Addiction, 99, 1042-1048. doi:10.1111/j.13600443.2004.00754.x

Heatherton, T. F., Kozlowski, L. T., Frecker, R. C., Rickert, W., \& Robinson, J. (1989). Measuring the Heaviness of Smoking: using self-reported time to the first cigarette of the day and number of cigarettes smoked per day. British Journal of Addiction, 84, 791-800. doi:10.1111/j.1360-0443.1989.tb03059.x

International Tobacco Control Policy Evaluation Project. (2010). FCTC article 14: Tobacco dependence and cessation. Waterloo, Canada: Author. Retrieved from http://www. itcproject.org/documents/keyfindings/itccessationreportpdf.

Kaper, J., Wagena, E. J., Willemsen, M. C., \& van Schayck, C. P. (2005). Reimbursement for smoking cessation treatment may double the abstinence rate: Results of a randomized trial. Addiction, 100, 1012-1020. doi:10.1111/i.1360-0443.2005.01097.x

Kaper, J., Wagena, E. J., Willemsen, M. C., \& van Schayck, C. P. (2006). A randomized controlled trial to assess the effects of reimbursing the costs of smoking cessation therapy on sustained abstinence. Addiction, 101, 1656-1661. doi:10.1111/ j.1360-0443.2006.01578.x

Kirk, R. E. (1996). Practical significance: A concept whose time has come. Educational and Psychological Measurement, 56, 746759. doi:10.1177/0013164496056005002

Kotz, D., Fidler, J., \& West, R. (2009). Factors associated with the use of aids to cessation in English smokers. Addiction, 104, 1403-1410. doi:10.1111/j.1360-0443.2009.02639.x

Lancaster, T., Stead, L. F., Silagy, C., \& Sowden, A. (2000). Effectiveness of interventions to help people stop smoking: Findings from the Cochrane Library. British Medical Journal, 321, 355-358. doi:10.1136/bmj.321.7257.355

Levy, D. T., Mabry, P. L., Graham, A. L., Orleans, T., \& Abrams, D. B. (2010). Exploring scenarios to dramatically reduce smoking prevalence: A simulation model of the three-part cessation process. American Journal of Public Health, 100, 1253-1259. doi:10.2105/AJPH.2009.166785

Lopez, A. D., Mathers, C. D., Ezzati, M., Jamison, D. T., \& Murray, C. J. L. (2006). Global and regional burden of disease and risk factors, 2001: Systematic analysis of population health data. The Lancet, 367, 1747-1757. doi:10.1016/S01406736(06)68770-9

Nagelhout, G. E., Willemsen, M. C., Thompson, M. E., Fong, G. T., van den Putte, B., \& de Vries, H. (2010). Is web interviewing a good alternative to telephone interviewing? Findings from the
International Tobacco Control (ITC) Netherlands survey. BMC Public Health, 10, 351. doi:10.1186/1471-2458-10-351

Partnership on smoking cessation. (2006). Guideline treatment of tobacco dependence. Alphen aan den Rijn, The Netherlands: Van Zuiden Communications. Retrieved from www.cbo.nl/ Downloads/201/tabak-eng-rl-2006.pdf

Pierce, J. P., Cummins, S. E., White, M. M., Humphrey, A., \& Messer, K. (2012). Quitlines and nicotine replacement for smoking cessation: Do we need to change policy? Annual Review of Public Health, 33, 12.11-12.16. doi:10.1146/ annurev-publhealth-031811-124624

Schafer, L. S., \& Graham, J. W. (2002). Missing data: Our view of the state of the art. Psychological Methods, 7, 147-177. doi:10.1037/1082-989X.7.2.147

Schnoll, R. A., Martinez, E., Tatum, K. L., Glass, M., Bernath, A., Ferris, D., et al. (2011). Increased self-efficacy to quit and perceived control over withdrawal symptoms predict smoking cessation following nicotine dependence treatment. Addictive Behaviors, 36, 144-147. doi:10.1016/j. addbeh.2010.08.024

Shiffman, S., Brockwell, S. E., Pillitteri, J. L., \& Gitchell, J. G. (2008a). Individual differences in adoption of treatment for smoking cessation: Demographic and smoking history characteristics. Drug and Alcohol Dependence, 93, 121-131. doi:10.1016/ j.drugalcdep.2007.09.005

Shiffman, S., Brockwell, S. E., Pillitteri, J. L., \& Gitchell, J. G. (2008b). Use of smoking-cessation treatment in the United States. American Journal of Preventive Medicine, 34, 102-111. doi:10.1016/j.amepre.2007.09.033

Silagy, C., Lancaster, T., Stead, L., Mant, D., \& Fowler, G. (2004). Nicotine replacement therapy for smoking cessation. Cochrane Database of Systematic Reviews, (3). CD000146. doi:000110.001002/14651858.CD14000146.pub 14651852

Sood, A., Ebbert, J. O., Sood, R., \& Stevens, S. R. (2006). Complementary treatments for tobacco cessation: A survey. Nicotine \& Tobacco Research, 8, 767-771. doi:10.1080/ 14622200601004109

Special Eurobarometer 362. (2011). E-communications household survey. Retrieved from http://ec.europa.eu/information_society/ digital-agenda/scoreboard/library/index_en.htm

STIVORO. (2011). Kerncijfers roken in Nederland 2010: Een overzicht van recente Nederlandse basisgegevens over rookgedrag [Core numbers on smoking in the Netherlands 2010: An overview of recent Dutch basic facts on smoking behavior]. The Hague, The Netherlands: STIVORO_for a smoke free future. Retrieved from http://www.stivoro.nl/Upload/Kerncijfers $\% 20$ roken $\% 20$ in $\% 20$ Nederland $\% 202010 \% 20$ $\% 282 \% 29 . p d f$

U.S. Public Health Service. (2000). A clinical practice guideline for treating tobacco use and dependence: A US Public Health Service report. Journal of the American Medical Association, 283, 3244-3254. doi:10.1001/jama.283.24.3244 
Van Ossenbruggen, R., Vonk, T., \& Willems, P. (2006). Results Dutch Online Panel Comparison Study (NOVPO). Retrieved from http://www.nopvo.nl

Weinstein, N. D., Slovic, P., \& Gibson, G. (2004). Accuracy and optimism in smokers' beliefs about quitting. Nicotine \& Tobacco Research, 6, 375-380. doi:10.1080/14622200412331320789

West, R., McNeill, A., Britton, J., Bauld, L., Raw, M., Hajek, P., et al. (2010). Should smokers be offered assistance with stopping? Addiction, 105, 1867-1869. doi:10.1111/j.13600443.2010.03111.x

White, A. R., Rampes, H., Liu, J. P., Stead, L. F., \& Campbell, J. L. (2011). Acupuncture and related interventions for smoking cessation. Cochrane Database of Systematic Reviews, (1). CD000009. doi:000010.001002/14651858.CD1400 0009.pub14651853

Willemsen, M. C., Wagena, E. J., \& van Schayck, C. P. (2003). De effectiviteit van stoppen-met-rokenmethoden die in
Nederland beschikbaar zijn: Een systematische review op basis van Cochrane-gegevens [The efficacy of smokingcessation methods available in the Netherlands: A systematic review based on Cochrane data]. Nederlands Tijdschrift voor Geneeskunde, 147, 922-927. Retrieved from http://www. ntvg.nl/publicatie/de-effectiviteit-van-stoppen-met-rokenmethoden-die-nederland-beschikbaar-zijn-eensystema/volledig

Williams, G. C., McGregor, H. A., Sharp, D., Levesque, C., Kouides, R. W., Ryan, R. M., et al. (2006). Testing a selfdetermination theory intervention for motivating tobacco cessation: Supporting autonomy and competence in a clinical trial. Health Psychology, 25, 91-101. doi:10.1037/0278-6133. 25.1.91

Zhu, S.-H., Melcer, T., Sun, J., Rosbrook, B., \& Pierce, J. P. (2000). Smoking cessation with and without assistance: A population-based analysis. American Journal of Preventive Medicine, 18, 305-311. doi:10.1016/S07493797(00)00124-0 